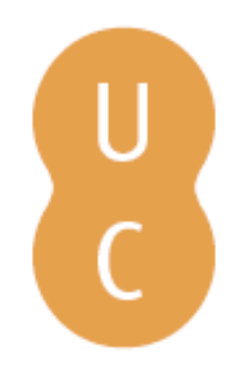

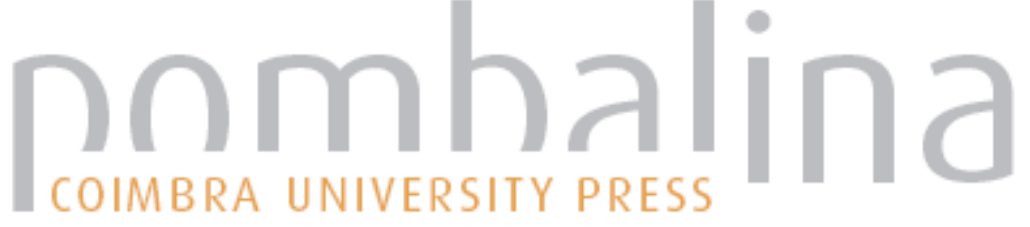

\section{A Ficção de João Aguiar: a alquimia de uma escrita múltipla}

Autor(es): $\quad$ Arnaut, Ana Paula

Publicado por: Imprensa da Universidade de Coimbra

URL

persistente:

URI:http://hdl.handle.net/10316.2/32569

DOI:

DOI:http://dx.doi.org/10.14195/978-989-26-0388-9_4

Accessed : $\quad$ 26-Apr-2023 05:07:40

A navegação consulta e descarregamento dos títulos inseridos nas Bibliotecas Digitais UC Digitalis, UC Pombalina e UC Impactum, pressupõem a aceitação plena e sem reservas dos Termos e Condições de Uso destas Bibliotecas Digitais, disponíveis em https://digitalis.uc.pt/pt-pt/termos.

Conforme exposto nos referidos Termos e Condições de Uso, o descarregamento de títulos de acesso restrito requer uma licença válida de autorização devendo o utilizador aceder ao(s) documento(s) a partir de um endereço de IP da instituição detentora da supramencionada licença.

Ao utilizador é apenas permitido o descarregamento para uso pessoal, pelo que o emprego do(s) título(s) descarregado(s) para outro fim, designadamente comercial, carece de autorização do respetivo autor ou editor da obra.

Na medida em que todas as obras da UC Digitalis se encontram protegidas pelo Código do Direito de Autor e Direitos Conexos e demais legislação aplicável, toda a cópia, parcial ou total, deste documento, nos casos em que é legalmente admitida, deverá conter ou fazer-se acompanhar por este aviso.

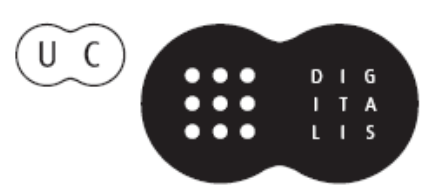


JOSÉ RIBEIRO FERREIRA

PAULA BARATA DIAS

Coordenação
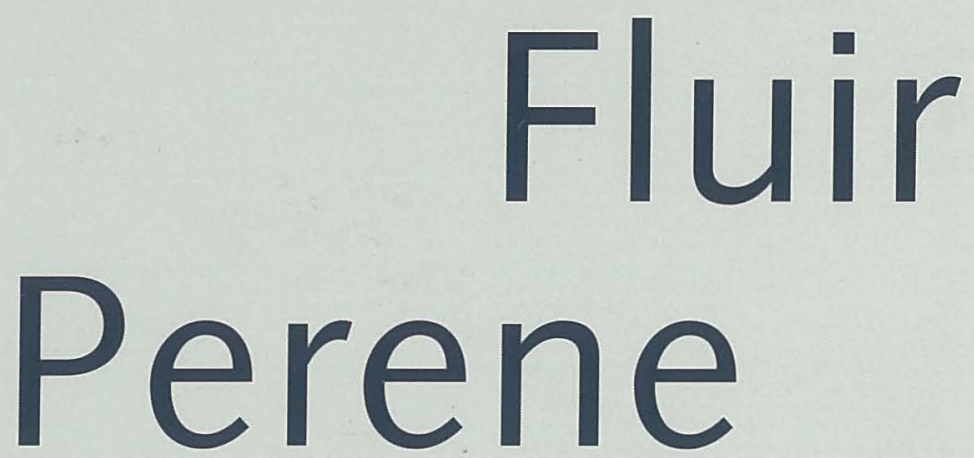

\section{A cultura clássica \\ em escritores portugueses \\ contemporâneos}


COORDENAÇÃO EDITORIAL

Imprensa da Universidade de Coimbra

CONCEPÇÃO GRÁFICA

António Barros

PAGINAÇÃO

António Resende

[Universidade de Coimbra]

EXECUÇÃO GRÁFICA

G.C. - Gráfica de Coimbra, Lda.

Rua do Progresso, 13 - Palheira - Assafarge

Telef.: 239802450 - Fax: 239802459

ISBN

972-8704-20-8

DEPÓSITO LEGAL

$211155 / 04$

(C) ABRIL 2004, IMPRENSA DA UNIVERSIDADE DE COIMBRA

OBRA PUBLICADA COM O APOIO DE: INSTITUTO DE ESTUDOS CLÁSSICOS 


\author{
JOSÉ RIBEIRO FERREIRA \\ PAULA BARATA DIAS \\ COORDENAÇÃO
}

\title{
Fluir Perene
}

\section{A cultura clássica em \\ escritores portugueses contemporâneos}

\author{
AUTORES \\ Fernando Pinto do Amaral \\ José Carlos Seabra Pereira \\ Maria Helena da Rocha Pereira \\ Ana Paula Arnaut \\ Luísa de Nazaré Ferreira \\ José Ribeiro Ferreira \\ Mário Garcia \\ Isabel Pires de Lima \\ Fernando Guimarães \\ Osvaldo Manuel Silvestre \\ Walter de Medeiros \\ Maria João Borges \\ Teresa Cristina Cerdeira da Silva
}

Coimbra • Imprensa da Universidade • 2004

MinervaCoimbra 



\author{
Ana PAUla ARnaut *
}

\title{
A FICÇÃO DE JOÃO AGUIAR: A ALQUIMIA DE UMA ESCRITA MÚLTIPLA
}

João Aguiar, jornalista e escritor já sobejamente conhecido no actual panorama literário, publicou até à presente data sete romances e um livro de contos: A Voz dos Deuses, 1984; O Homem Sem Nome, 1986; O Trono do Altíssimo, 1988; O Canto dos Fantasmas (contos), 1990; Os Comedores de Pérolas, 1992; A Hora de Sertório, 1994; A Encomendação das Almas, 1995; Navegador Solitário, 1996. Conjunto de obras que consideramos semelhantes em termos de marcas de estilo, mas que, no que diz respeito à sua semântica global e aos registos que a ela subjazem preferimos considerar como uma escrita múltipla.

Concerne esta alegada multiplicidade não apenas a possibilidade de identificar as coordenadas estéticas por que se norteia a produção literária de João Aguiar — os caminhos da História e das Estórias. Diz outrossim respeito ao modo como, no grupo dos romances de temática histórica, o autor entretece dados históricos com elementos ficcionais; e como, nas narrativas de ficção, a sua capacidade imaginativa, aparece, por vezes, travestida por cores fantásticas, feéricas (O Homem Sem Nome); por laivos de realidade vivida ou sabida por outrem ( $O$ Canto dos Fantasmas); por características das narrativas policiais (Os Comedores de Pérolas); ou ainda ancorada no folclore popular e na realidade portuguesa (A Encomendação das Almas e Navegador Solitário).

Da intromissão de elementos ficcionais na tessitura narrativa de carácter histórico, dá-nos João Aguiar conta na Advertência Prévia ao primeiro dos seus romances - A Voz dos Deuses -, e igualmente válida, lato sensu, para os romances A Hora de Sertório e O Trono do Altíssimo:

$\left(^{*}\right)$ Faculdade de Letras da Universidade de Coimbra. 
«Boa, má ou simplesmente medíocre, «A Voz dos Deuses» é uma obra de ficção e não um ensaio histórico rigoroso. No entanto, estou sinceramente persuadido de que $\circ$ Viriato que os leitores encontrarão nestas páginas está mais próximo do Viriato histórico e verdadeiro que a tradicional imagem do rude pastor dos Hermínios bravamente entricheirado na sua cava, em Viseu; mesmo porque Viriato não nasceu nos Hermínios (...) e a Cava é uma fortificação que nada tem a ver com o chefe lusitano.

Entretanto, e parafraseando Eça de Queirós (...), foi necessário lançar sobre a nudez forte de uma verdade histórica insuficiente o manto diáfano de uma fantasia plausível ou, pelo menos, aceitável (...)».

É, pois, de acordo com este jogo entre História e ficção, cujas regras tacitamente se acordam com o leitor, que João Aguiar recua aos mais remotos tempos de Viriato, de Sertório e de Prisciliano. Destes, e da época em que se movimentam, aproveita, por um lado, alguns aspectos históricos, oficialmente tornados verdadeiros por todos os que, em diferentes espaços e tempos, foram investidos do poder de fazer crónica do passado. Por outro, o que o Autor leva a cabo mais não é do que a consecução da noção Ingardiana de preenchimento de pontos de indeterminação (Ingarden, 1973:366) provocados, e permitidos, pela pretensa objectividade dos relatos históricos ortodoxamente científicos, deste modo construindo verdades internas da ficção, tão didácticas e úteis como as verdades oficiais.

$\bigcirc$ que John Woods designa por modalidades mistas de existência (Woods, 1974:41-42) ocorre em A Voz dos Deuses, A Hora de Sertório e O Trono do Altíssimo, não apenas pela convivência no universo narrado de personagens, acontecimentos e lugares aceites como históricos, com personagens, acontecimentos e espaços ficcionais, mas também, e essencialmente, pelo facto de em cada uma dessas categorias coexistirem as duas linhas de força: a histórica e a ficcional.

Desta feita, por exemplo, coexistem em A Voz dos Deuses personagens, acontecimentos, tradições e modos de vida reais - Viriato, Sérvio Galba (governador da província Ulterior), Luculo (governador da Citerior), Gaio Vetílio, responsável pela corrupção de Audax, Ditalco e Minuro, assassinos do chefe lusitano - com personagens e acontecimentos fictícios, mas não inverosímeis - caso de Tongio, companheiro de Viriato e futuro sacerdote 
do templo de Endovélico; caso dos oráculos de Baikor e da Serra da Lua, cuja descrição, entre muitas outras, activa esquemas cognitivos conformes ao que o leitor julga ter sido o estado das coisas da época em causa. Cite-se, a título de ilustração, e no que diz respeito ao mundo das crenças, uma breve passagem alusiva à profecia da Serra da Lua:

«Relancei um olhar alarmado à nossa volta e nesse instante ouvi uma espécie de silvo, como se fosse uma cobra, e logo a seguir a voz soou de novo - e saía da boca de Arduno, mas não era ele que falava nem era a sua voz; parecia a de uma mulher, embora o som fosse grave a articulação dura e enérgica.

- Tongio, filho de Tongétamo. Porque fazes perguntas sobre o destino se os deuses já te disseram o que podias ouvir? À vossa frente - caminho é longo. Há vitórias e derrotas, alegria e sangue, traição e glória. A águia está ferida mas este é o tempo do seu domínio. Depois do Touro virá a Corça. Porque fazes perguntas? É tempo de combater. Só tu verás a era da Corça. Mas os deuses querem-te, os deuses surgirão no teu caminho...» (p. 178).

«Depois do Touro virá a Corça...». Depois de Viriato é A Hora de Sertório, é altura de encerrar o díptico, compondo, dez anos depois, as voltas ao mote dado pela profecia, numa narração a três vozes dos valores e das crises sociais, económicas e políticas do mundo romano do século I a.C.

A polifonia narrativa deixa de ser protagonizada pela voz dos deuses, até porque «Os deuses calaram-se no céu e na terra» (p. I I), e passa a ser entabulada entre Euménio de Rodes, Lúcio Hirtuleio e Medamo. Narradores do trajecto pessoal e político de Quinto Sertório, estes são simultaneamente personagens, protagonistas por vezes, de pequenos quadros a partir dos quais é possível conhecer diversos aspectos da vida coetânea: cenários, usos e costumes da vida doméstica, cultural, social e política.

Conhecemos e sabemos o que eles conhecem, sabem e testemunham; informações que, apesar de limitadas e parciais, validam os relatos feitos, porquanto estes se crêem tanto mais verídicos e credíveis quanto tiverem sido «efectivamente» vividos pela entidade que preside à narrativa. Além disso, aduza-se ao exposto que a mencionada limitação, de certo modo inerente aos narradores homodiegéticos, é colmatada pelo facto de cada 
voz ir progressivamente preenchendo vazios, momentos da narrativa deixados em aberto pela voz anterior.

Registem-se a propósito, dois exemplos que consideramos elucidativos:

I. no Terceiro Fragmento, Euménio de Rodes alude, sucintamente, às crises políticas que levam Cinna, Sertório e os outros chefes populares a fugir de Roma para outras regiões de Itália, onde organizam a resistência e a revolta que levará ao cerco e posterior capitulação de Roma. Se alguns pormenores sabemos acerca dos padecimentos na cidade cercada, praticamente nada é referido sobre o modo como os acontecimentos se precipitaram. A narrativa só é preenchida quando a voz de Euménio de Rodes cede lugar à voz de Lúcio Hirtuleio, fiel amigo e colaborador de Sertório, testemunha e participante dos acontecimentos que agora lhe cumpre relatar.

2. no capítulo intitulado «A Corça», cabe a Medamo não só dar a sua versão sobre uma pequena parte do seu tempo de infância, como também, e sobretudo, continuar e concluir a narrativa sobre Sertório, não sem antes ter dado conta dos acontecimentos que cumprem a profecia da voz da deusa da Serra da Lua.

Este procedimento pluridiscursivo havia já aparecido ensaiado em 0 Trono do Altíssimo, romance cuja trama gira à volta da evolução e declínio do Priscilianismo, doutrina de filiação gnóstica que durante cerca de dois séculos (IV e $\vee$ d.C.) disputou terreno com a ortodoxia católica. Assim, neste romance o narrador heterodiegético, cada vez menos omnisciente, cede, por isso, temporariamente lugar a outros registos e a outras vozes.

Deste modo, no Livro I, é Restituto quem faz o relato da viagem a Roma, onde uma embaixada de Priscilianistas se desloca com o duplo intuito de esclarecer Dâmaso, o «santo papa romano», sobre aspectos fundamentais da doutrina, refutando as acusações de heresia, gnosticismo e maniqueísmo e de, na corte, obter a anulação do rescrito que desterrava alguns bispos priscilianistas.

No Livro II, é através do discurso epistolar entre Quintiano e Restituto (390-409 a.c.), cuja «perícia como contador da verdade» o primeiro atesta, que conhecemos os «negros anos de 384-385» em que, sob um império repartido por três Augustos, se intensificam as perseguições aos seguidores desta doutrina, que culminam com a execução em Tréveris de Prisciliano e alguns companheiros. 
No Livro III, novamente se ouve a voz do narrador, agora coadjuvado por Vitimer, noviço no mosteiro de Dume, cujos pensamentos e actos servem de trilho para conhecer umas últimas epístolas de Quintiano, religiosamente guardadas porque a serem divulgadas «lançariam a desordem entre os simples» e «a santa fé católica deve ser defendida a todo o custo», guardando-se «contra cismas e traições heréticas» (p. 347). Porque, acrescentamos nós, poriam em causa uma verdade construída de acordo com interesses particulares da instituição religiosa.

Mantêm-se, em suma, as traves mestras da História - de resistência contra a opressão da República Romana, de lutas pelo poder em Roma, de tentativas de implementar novas doutrinas —, sustentadas por traves de menor envergadura, mas não menos importantes, até porque representam o resultado de um aturado trabalho de investigação, que o autor não renega, mas que, tal como Garrett, «sacrifica às musas de Homero, não às de Heródoto: e quem sabe, por fim, em qual dos dois altares arde o fogo de melhor verdade» (Garrett, 1973:39).

Criam-se, afinal, pequenos mundos possíveis (Albaladejo, 1986:58-59) em que, e também porque as palavras e os actos das personagens não entram em conflito com as canónicas versões dos historiadores (Halsall, 1984:81), é difícil destrinçar fronteiras nítidas entre a verdade histórica e a verdade ficcional, apesar de alguma clarificação ser facultada pelas Notas Finais. Sublinhamos 'alguma clarificação' porque, segundo cremos, e já o dissemos por outras palavras, a investigação histórica é, à partida, viciada e selectiva, logo pretensamente objectiva. De acordo com Elisabeth Wesseling essa selectividade radica em três diferentes causas, a primeira das quais diz respeito ao facto de apenas se poder investigar o que conseguiu sobreviver até à nossa época; a segunda prende-se com as questões que se pretende ver respondidas, o que leva à selecção de certas fontes em detrimento de outras; a terceira é uma causa política, na medida em que a História apenas se preocupa em deixar os registos de indivíduos e colectividades que, num dado tempo, por obras e feitos se destacaram (Wesseling, |99|:|25-126).

Julgamos, contudo, e para terminarmos esta breve incursão pelos romances históricos de João Aguiar, que nada melhor do que as palavras de um autor clássico para validar os processos de um autor contemporâneo cuja obra, não só mas também, revive e reescreve legados da cultura clássica: 
«(...) não é ofício de poeta narrar o que aconteceu; é, sim, o de representar o que poderia acontecer, quer dizer: o que é possível segundo a verosimilhança e a necessidade. Com efeito, não diferem o historiador e o poeta, por escreverem verso ou prosa (...) - diferem, sim, em que diz um as coisas que sucederam, e outro as que poderiam suceder»».

(Aristóteles, 1994:1 15)

«As [coisas] que poderiam suceder», a (re)construção hipotética e verosímil de momentos de um passado distante; de situações de um passado próximo - a época colonial, por exemplo - ou de um mundo projectado no futuro, já não distante, do ano 2023. Falamos, agora, de O Canto dos Fantasmas, colectânea de pequenas estórias «não totalmente imaginadas»(à excepção da última) pois «Há nelas muita ficção mas baseiam-se em factos, ○ que me obrigou a alterar os nomes de alguns personagens» (p. 9). Pequenas estórias, dizíamos, ensombradas por pequenos grandes fantasmas que, na impossibilidade de se apresentarem a viva voz, consubstanciam-se em manifestações sobrenaturais de difícil explicação (Primeira parte: fantasmas, espíritos e fenómenos) ou em obsessões humanas, de índole diferente mas não menos fantasmagórica, e de que é exemplo o conto «Enfim, o Paraíso» (Segunda parte: outras assombrações).

Neste conto (cujo enredo decorre no século XXI) Adriano Almeida é o porta-voz dos fantasmas e medos resultantes da criação de uma Federação Europeia, onde os preços são calculados em delornis, constituída por Regiões cujas bandeiras nacionais foram já substituídas pelas «estrelas federais e douradas, em campo azul», mantendo-se as bandeiras com símbolos nacionais, no interior do círculo de estrelas, apenas para «uso interno das Regiões»(p. 224) cujos dirigentes, «entrincheirados em Bruxelas», tudo decidem sem o menor respeito pelas identidades nacionais. Por isso se afirma:

A Federação não construiu a Europa; deitou ao mundo um aborto político, económico e espiritual em torno de três grandes países poderosos a que eufemisticamente chamamos Grandes Regiões e Arqui-Região. A Europa Federada não nasceu de parto natural: nasceu à força de subsídios, concedidos ou recusados segundo o clássico sistema do bastão e da cenoura» (p. 227). 
Em função do exposto, se concordamos com o autor quando afirma que «Enfim, o Paraíso é um puro divertimento», dele discordamos quando aduz tratar-se de «uma fantasia ingénua e inocente», na medida em que se especulam, ainda que, por vezes, de modo subliminarmente irónico e bem-humorado, algumas das preocupações que fizeram, fazem parte integrante da realidade coeva e nacional, por vezes mais absurda que qualquer narrativa de ficção!

Missão do escritor pode ser também a de criar mundos fantásticos, como esse que encontramos em 0 Homem Sem Nome, segundo romance do autor em apreço, onde as personagens povoam um universo suspenso num tempo e num espaço indefinidos.

Assim, se por vezes sobressai a impressão de se tratar de um mítico tempo passado colorido por palácios, reis e rainhas, tribos nómadas e deuses diversos; em outros passos é-nos entreaberta a porta do que parece ser um futuro apresentado com vagos traços de ficção científica, como acontece, por exemplo, com a referência aos tubos-de-raio e canhões-de-raio, armas utilizadas pelos Khrâmitas.

Outros momentos há em que o enunciado mais parece referir-se a aspectos, quase diria preocupações, do presente. É este o caso da poluição das águas de Dagh com dejectos de milhares de fábricas, da urbanização desenfreada de locais paradisíacos como a llha da Serpente ou dos intuitos políticos da Grande Oligarquia de Hezhrad-Oth que, depois da revolução popular que lhe deu origem, pretende levar todos os povos do Continente a aderir a um Novo Sistema, ideal e correcto nos seus princípios de «pão, paz, liberdade total e total prosperidade», mas errado na sua aplicação já que a adesão visa ser conseguida pela força da guerra e das instituições prisionais.

A aura de mistério e de fantástico que preside a este romance decorre, também, do modo como as personagens são caracterizadas, da cor que é dada aos espaços em que se movimentam; mas decorre, essencialmente, da forma como o protagonista atravessa todas as páginas do romance. Dele não saberemos o nome, nem a origem, nem de onde lhe vem a voz mágica que, mais do que seduz, encanta todos os que o ouvem; não será, muito menos, justificado o halo brilhante que o envolve enquanto o seu vulto se perde no horizonte.

De mistério se fala também em Os Comedores de Pérolas, mas agora um mistério de natureza diferente, pois não se reporta apenas a um 
enraizamento no fantástico (em que entra Lei Siu Lam, criação e amigo imaginário do protagonista). Relaciona-se, sim, com a ideia de suspense, criado ao modo das narrativas pertencentes ao subgénero policial, e que, no presente caso, surge enformado numa escrita diarística em que o narrador, autodiegético, intermitentemente anota os incidentes da sua estada em Macau.

Este diário é simultaneamente encarado como «ordenador de ideias» e «registo paralelo de cuja existência ninguém tem conhecimento» (p. 62). Medida de prevenção que a Adriano Carreira se afigura como necessária, visto que o perigo de vida aumenta na medida proporcional aos conhecimentos facultados, quer pelo espólio do Comendador Wang Wu, quer por informações e investigações paralelas que leva a cabo.

A trama de suspense que envolve a narrativa encontra eco não apenas na tentativa de descobrir o verdadeiro motivo das perseguições, ciladas e atentados. Com efeito, nos primeiros cofres do espólio, o protagonista depara com algumas frases herméticas que contribuem para o adensamento da teia de mistério e, consequentemente, para um maior envolvimento do leitor, pois também ele vai tentar decifrar o enigma, juntando as peças do puzzle que progressivamente se forma.

Orquestrada com base no jogo lúdico inerente às narrativas policiais, a efabulação de Os Comedores de Pérolas tece, também, apreciações críticas e irónicas à realidade social que em Macau se vive, nestes anos que antecedem a sua reintegração na China, e, simultaneamente, à mentalidade de uma época que é, em suma, a nossa.

A Encomendação das Almas e Navegador Solitário dão continuidade a duas grandes linhas de orientação que já encontrámos em obras anteriores: a preocupação com a realidade social contemporânea, por um lado, o gosto pelos imbricados caminhos do fantástico, por outro. Assim, em ambos o mesmo fascínio pelo sobrenatural, apresentado em diversas facetas, mas que, todavia, e apesar de diferentemente servir as personagens dos dois romances, dá serventia a intuitos críticos e caricaturais semelhantes.

Deste modo, o mundo que demiurgicamente Gonçalo Nuno e Zé da Pinta vão construindo na Casa Velha, mundo enraizado na vastíssima tradição popular das moiras encantadas, lobisomens e Seculares das Nuvens, representa a saída possível para o mundo real e hostil que não se revela, ainda, apto a lidar com os problemas da terceira idade ou dos apoucados 
como Zé da Pinta. Por isso, entre essa realidade minada «pela poluição física e mental» e essoutra em que vivem os Seculares das Nuvens, de bom grado os protagonistas optam pela última.

Em Navegador Solitário, o elemento sobrenatural serve, não este propósito de permitir a alienação do real mas, pelo contrário, essoutro de facultar ao protagonista, Solitão Francisco Fernandes, a aprendizagem necessária à sua entrada numa realidade social em que imperam diversas formas de imoralidade e de falta de escrúpulos!

A polifonia narrativa, essencialmente instaurada pela voz do avô Aquilino, que se faz ouvir quer através das capacidades mediúnicas dessa caricata figura que é Preciosa, quer através de um processo de escrita automática que obriga Solitão a escrever, cumpre, agora, um objectivo bem diferente desse a que aludimos a propósito de outros romances. Com efeito, essa voz não é credora do tom sério e objectivo de quem faz depoimento histórico; pelo contrário, revela um tom jocoso de quem carnavaliza, no sentido bakhtiniano, a realidade social contemporânea, deste modo a utilizando como matéria-prima essencial à consecução de pertinazes e acutilantes críticas que, embrionariamente, percorrem anteriores escritos de João Aguiar.

Em função do exposto, e recordando as palavras do autor em entrevista concedida ao Jornal de Letras há cerca de seis anos, acreditamos que a sua obra conquistou, de pleno direito, um lugar de prestígio «numa (...) das gavetinhas literárias portuguesas» (Aguiar, 1990:8).

\section{BIBLIOGRAFIA ACTIVA}

Aguiar, João (s/d), A Voz dos Deuses. 12. a ed. Lisboa: Perspectivas \& Realidades.

- O Homem Sem Nome. 6. a ed. Porto: Asa, 1994.

- O Trono do Altíssimo. 3. a ed. Porto: Asa, 1995.

- O Canto dos Fantasmas. Lisboa: Dom Quixote, 1990.

- Os Comedores de Pérolas. 6. ${ }^{\mathrm{a}}$ ed. Porto: Asa, 1995.

- A Encomendação das Almas. 2. a ed. Porto : Asa, 1996.

- Navegador Solitário. Porto: Asa, 1996.

- Jornal de Letras, Artes e Ideias, 15 de Maio, 1990. 


\section{BIBLIOGRAFIA TEÓRICA}

AlBALADEjO, Tomás Mayordomo - Teoria de los mundos posibles y Macroestrutura Narrativa. Alicante : Univ. de Alicante, 1986.

ARISTÓteles - Poética, 4.a ed., Tradução, Prefácio, Introdução, Comentário e Apêndices de Eudoro de Sousa. Lisboa: IN-CM, 1994.

GARRETT, Almeida - Frei Luís de Sousa. Coimbra : Atlântida, 1973.

HALSALL, Albert - «Le roman historico-didactique». In : Poétique 57, Paris : Ed. Seuil, 1984.

INGARDEN, Roman - A obra de arte literária. Lisboa : Fundação Gulbenkian, 1973.

WESSELING, Elisabeth - Writing History as a Prophet. Amsterdam / Philadelphia, John Benjamins, 1991.

Woods, John - The Logic of Fiction. Paris: Mouton, 1974. 

Investigaçăo

Coimbra

Imprensa da Universidade

MinervaCoimbra

2004 